\title{
Embalagens retornáveis para transporte de bens manufaturados: um estudo de caso em logística reversa
}

\author{
Diogo Adlmaier \\ Miguel Afonso Sellitto \\ Universidade do Vale do Rio dos Sinos
}

\begin{abstract}
Resumo
Este artigo descreve um estudo de caso em logística reversa sobre embalagens retornáveis adequadas para transporte internacional de peças para motores a diesel. O estudo diz respeito a cabeçotes exportados do Brasil para os Estados Unidos da América, por via marítima. Inicia-se por uma revisão em logística reversa. A seguir descreve-se o caso, com base em informações colhidas pelos pesquisadores junto à empresa. Descrevem-se os fatos, investigam-se as causas que os originaram e compara-se o processo original de exportação, com embalagens descartáveis, com o novo processo, com embalagens retornáveis, que opera um canal de distribuição reverso. Avaliaram-se os ganhos financeiros, logísticos e ambientais do projeto, de forma a relacionar criticamente a teoria com a prática.
\end{abstract}

Palavras-chave

Logística reversa, embalagens retornáveis, gestão ambiental.

\section{Returnable packaging for transportation of manufactured goods: a case study in reverse logistics}

\begin{abstract}
This paper describes a case study in reverse logistics, dealing with returnable packaging, suitable for international transportation of parts required by diesel engines assembly operations. The study refers to cylinder heads, exported from Brazil to USA, by sea. The paper begins by revisiting issues in reverse logistics. Then describes the case, supported by information gathered by researchers with technical personnel from the firm. Beyond the pure facts, the researchers aimed to find out why the firm took such a decision, comparing the exportation process, how it was and how it is now, and the operation of a reverse distribution channel. The text assesses financials, logistics and environmental benefits from the actions, relating critically theory and practice.
\end{abstract}

Key words

Reverse logistics, returnable packaging, environmental management. 


\section{INTRODUC̣̃̃O}

A logística reversa vem sendo reconhecida como a área da logística empresarial que planeja, opera e controla o fluxo e as informações logísticas correspondentes ao retorno de bens ao seu ciclo produtivo de origem ou à sua destinação, como matéria-prima, a outro ciclo produtivo. $\mathrm{O}$ bem pode retornar em forma próxima à original, como retorno pósvendas, ou em forma de resíduos, rejeitos ou refugos, como retorno pós-consumo. O retorno pós-vendas é devido, principalmente, a problemas de qualidade, tais como defeitos de fabricação ou erros de projeto, e a problemas comerciais, tais como erros de expedição, consignações não requisitadas, sobras de promoções, obsolescência tecnológica ou de moda e perda de validade. O retorno pós-consumo se dá, principalmente, pela incapacidade de quem consome o bem de dar destinação adequada às partes resultantes do consumo ou aos resíduos. econômicos e ambientais. Leite e Brito (2003) apontam a logística reversa como oportunidade de gerar valor a clientes, seja pela coleta e processamento de resíduos potencialmente perigosos, seja dando nova destinação a bens já utilizados, mas que ainda possuem algum tipo de valor.

$\mathrm{O}$ descarte de embalagens industriais é um processo que pode ser especialmente problemático em fluxos reversos. Embalagens industriais retornáveis específicas, não padronizadas, podem reduzir o descarte e ainda proporcionar melhor aproveitamento de espaço no transporte. Um caso importante ocorre na exportação de bens manufaturados. Neste caso, custos elevados e legislações específicas podem viabilizar o desenvolvimento deste tipo de embalagem.

O objetivo deste artigo é apresentar um estudo de caso, em que são enumerados e analisados os ganhos proporcionados pela adoção de embalagens retornáveis por uma empresa fabricante de motores a diesel, em sua operação de exportação de cabeçotes de motores do Brasil para os Estados Unidos da América. $O$ caso faz parte das atividades do grupo de pesquisa em planejamento da competitividade empresarial, do PPGEPS da UNISINOS. O restante deste artigo contém uma revisão bibliográfica, a metodologia de pesquisa e de trabalho, uma discussão crítica do caso e conclusões e direções para continuidade de pesquisa.

A literatura sobre logística reversa trata essencialmente de modelos quantitativos, estudos de caso e tentativas

A fronteira entre logística direta e reversa não é estritamente definida, na medida em que os conceitos de matériaprima e de cliente final podem ser relativizados em algumas cadeias produtivas. Carros sucateados, por exemplo, são importante matéria-prima para aciarias equipadas com fornos elétricos a arco voltaico.

Fluxos reversos desempenham papel central na estratégia de empresas que vendem por catálogo ou em consignação. Nestes casos, a produção ocorre antes que se tenha a perspectiva exata do potencial de venda, o que faz com que compradores intermediários, eventualmente, tenham que devolver ou mudar a localização de itens não vendidos (DAUGHERTY; MYERS; RICHEY, 2002). A alocação de estoques de segurança em cadeias produtivas e de distribuição é outra estratégia que pode requerer fluxos reversos para a recuperação e retorno de itens não mais necessários (MINNER, 2001).

A logística reversa se insere em um processo de revisão conceitual da manufatura, na medida em que esta passou a discutir os impactos econômicos e ambientais da produção mais limpa em suas estratégias de negócios. Gaither e Frazier (2002) apresentam exemplos de empresas que mudaram estratégias de manufatura e logística e obtiveram benefícios de construção de teorias (BRITO; DEKKER, 2003). Fontes de pesquisa em logística reversa foram úteis em diversos momentos deste trabalho, citando-se: Brito e Dekker (2003), que apresentam uma revisão histórico-bibliográfica e um quadro de referência sobre logística reversa, e Dowlatshahi (2000), que caminha em direção a uma teoria de logística reversa; Kroon e Vrijens (1995), Pohlen e Farris (1992), Shih (2001) e Rodrigues e Pizzolato (2003), que apresentam e discutem casos de aplicação de logística reversa em indústrias específicas; Fleischmann et al. (1997), Fleischmann et al. (2001), Krumwiede e Sheu (2002) e Richey et al. (2005), que apresentam modelos com alguma generalidade; Daugherty; Myers e Richey (2002) e Daugherty et al. (2005), que estudam a importância dos sistemas e da tecnologia de informação em logística reversa; Rosenau et al. (1996) e Georgiadis e Vlachos (2004), que associam a logística reversa e desempenho ambiental; e Prahinski e Kocabasoglu (2006), que apresentam direções para pesquisas e uma lista de referências. Finalmente, Rogers e Tibben-Lembke (2001) e Leite e Brito (2003) apresentam surveys, que investigaram a natureza e as motivações para operações de logística reversa em múltiplas indústrias. 


\section{LOGÍSTICA REVERSA E EMBALAGENS RETORNÁVEIS}

Termos como canais reversos ou fluxos reversos têm sido usados desde os anos 1970. Estes termos, em princípio, têm sido mais usados em operações ligadas a reciclagem de materiais e gerenciamento ambiental, sendo menos associados a objetivos de redução de custo e aumento de valor econômico (BRITO; DEKKER, 2003).

Para que se compreenda a motivação das operações reversas, deseja-se revisitar algumas das definições e considerações acerca de logística reversa que foram encontradas na literatura. Justifica-se a revisita pela observação de Leite (2003) de que o conceito de logística reversa ainda está em evolução e ainda não se chegou a uma visão unificada, portanto entende-se que valha a pena agregar múltiplas perspectivas. De uma perspectiva gerencial, a logística reversa pode ser tratada como um sistema a ser gerenciado e as técnicas nela usadas podem ser integradas, formando a RLM (reverse logistics management, gestão da logística reversa).

A primeira definição conhecida de logística reversa foi publicada pelo então denominado Conselho de Gerenciamento Logístico (Council of Logistics Management, CLM), precursor do atual Conselho de Profissionais de Gerenciamento de Cadeias de Suprimentos (Council of Supply Chain Management Professionals, CSCMP), no início dos anos 1990 (STOCK, 1992, apud BRITO; DEKKER, 2003, p. 2):

“[...] logística reversa é o termo geralmente usado para referir o papel da logística na reciclagem, disposição de resíduos e gerenciamento de materiais perigosos; uma perspectiva mais ampla se relaciona com atividades logísticas de redução de fontes de abastecimento, reciclagem, substituição, reuso de materiais e disposição".

Talvez por ser uma visão inicial, esta definição ainda estava mais ligada à gestão ambiental. Pohlen e Farris (1992) introduzem a direcionalidade de fluxo e definem logística reversa como o movimento de bens que partem do consumidor e seguem em direção ao produtor, em um canal de distribuição que opera na direção oposta à original. Kopicky (1993, apud BRITO; DEKKER, 2003) introduz os termos "hazardous or non-hazardous waste from packaging and products", fugindo do cenário puramente ambiental e introduzindo definitivamente os aspectos econômicos no reaproveitamento de embalagens e produtos.

Em auto-citação de 1999, Rogers e Tibben-Lembke (2001) descreveram a logística reversa como o processo de planejamento, implementação e controle de fluxos de matérias-primas, inventário em processo, bens acabados e informações, desde o ponto de consumo até o ponto de origem, com o objetivo de recuperar valor ou fazer uma apropriada disposição ambiental. O Grupo Europeu de Trabalho em Logística Reversa modificou esta definição (BRITO; DEKKER, 2003), afirmando que a logística reversa é o processo de planejamento, implementação e controle de fluxos de matérias-primas, inventário em processo, bens acabados, partindo de uma manufatura, ponto de distribuição ou ponto de uso, em direção a um ponto de recuperação ou a um ponto de apropriada disposição ambiental.

\section{ao produtor, em um canal de distribuição que opera na direção oposta à original}

O RLEC (Reverse Logistics Executive Council - Conselho Executivo de Logística Reversa) (2004) define a logística reversa como o processo de movimentação de mercadorias do seu destino final típico para outro ponto, com o objetivo de obter um valor que de outra maneira estaria indisponível, ou, ainda, para a disposição final dos produtos. Segundo o Conselho, as atividades de logística reversa incluem: (i) processamento do retorno de mercadorias por danos, sazonalidade, reestocagem, salvados, recall, ou excesso de estoque; (ii) reciclagem ou reutilização de embalagens; recondicionamento ou remanufatura de produtos; e (iii) descarte de equipamentos obsoletos; controle de materiais perigosos ou recuperação de patrimônio.

A logística reversa também considera processos de retorno para reciclagem, reparação e remanufatura de itens e desempenha o papel de planejamento, execução e controle dos fluxos e de informações logísticas, pela própria cadeia de distribuição integrada ou por meio de cadeias especializadas em distribuição reversa. As atividades de logística reversa incluem transporte, armazenagem, distribuição de itens e gerenciamento de estoques (LEITE, 2003; CLM, 1993; MINNER, 2001; CHOUINARD; D’AMOURS; AITKAI, 2005; SHIH, 2001; PRAHINSKI e KOCABASOGLU, 2006). Em suma, a logística reversa engloba a totalidade dos processos de movimentação de bens, partindo da sua destinação inicial e chegando a um ponto no qual algum valor ainda inerente ao bem possa ser extraído, ou, ao menos, uma disposição final adequada possa ser feita (ROSS 1998, apud DAUGHERTY et al., 2002).

Sintetizando as perspectivas revisitadas, entende-se que a 
logística reversa pode ser descrita como a área da logística empresarial que visa a gerenciar, de modo integrado, todos os aspectos logísticos do retorno dos bens ao ciclo produtivo, por meio de canais de distribuição reversos de pósvenda e de pós-consumo, agregando-lhes valor econômico e ambiental. A logística reversa estuda os canais reversos de distribuição; canais estes que seguem fluxo oposto ao da cadeia original de distribuição de materiais, visando a agregar valor ao retorno pela sua reintegração a um ponto do ciclo produtivo de origem, ou a outro ciclo produtivo, sob a forma de insumo ou matéria-prima.

De modo geral, as atividades de logística reversa se integram com as de logística direta, segundo um fluxo de ida e vinda de materiais, como representado pela Figura 1.

\section{Aspectos ambientais da logística reversa}

$\mathrm{O}$ crescente interesse pela proteção ambiental aportou novas necessidades aos processos logísticos. Na Europa, o enfoque ambiental dado à logística reversa é apoiado por diretrizes legais para transporte e descarte de embalagens. Alguns países possuem legislação acerca do retorno de embalagens, tanto para reutilização quanto para descarte das mesmas. No Brasil, a legislação exige o retorno de produtos considerados perigosos após o término da vida útil, por conter metais pesados, tais como pilhas e baterias, e de produtos considerados problemáticos, devido às poucas opções de tratamento, como pneus. Nestes casos, a responsabilidade pela logística e pelo tratamento dos resíduos é do fabricante.

Segundo Slijkhuis (2004), a Comunidade Européia, com o uso da Diretiva 94/62, estabeleceu uma hierarquia de medidas para a redução de resíduos em prazos estabelecidos: (i) reduzir os resíduos na origem; (ii) utilizar materiais recicláveis; (iii) reutilizar os materiais, maximizando o giro; (iv) implementar sistemas de recuperação; e (v) reciclar os materiais.

A logística reversa tem sido associada a operações de reciclagem e a interesses de preservação ambiental, principalmente quanto a retornos de produtos não-consumidos ou de itens com defeitos de fabricação ou projeto, os recalls. Se estes itens não forem recolhidos, o consumidor, por falta de outros meios, poderá fazer a disposição de modo inadequado (DAUGHERTY, MYERS; GLENN, 2002; MINAHAN, 1998).

A prática da logística reversa é diferente da gestão ambiental, haja vista que esta se preocupa principalmente em recolher e processar rejeitos, refugos e resíduos de itens para os quais não há outro uso, enquanto que aquela se concentra em itens com valor a recuperar. A logística reversa tem afinidades com a chamada logística verde, haja vista que esta considera aspectos ambientais em atividades logísticas, tais como consumo de recursos naturais, emissões atmosféricas, uso de rodovias, poluição sonora e disposição de resíduos perigosos. A redução da necessidade de acondicionamento ou aumento da eficiência de transporte é um objetivo da logística verde, mas não da logística reversa. Já um estudo de embalagens reutilizáveis que substituem embalagens descartáveis, tal como o ora proposto, é objetivo tanto da logística verde como da reversa (ROGERS; TIBBEMLEMBKE, 2003).

Leite (2003) comenta que a imagem corporativa é atingida por questões ambientais e constata que organizações

Figura 1: Representação esquemática dos processos logísticos direto e reverso.

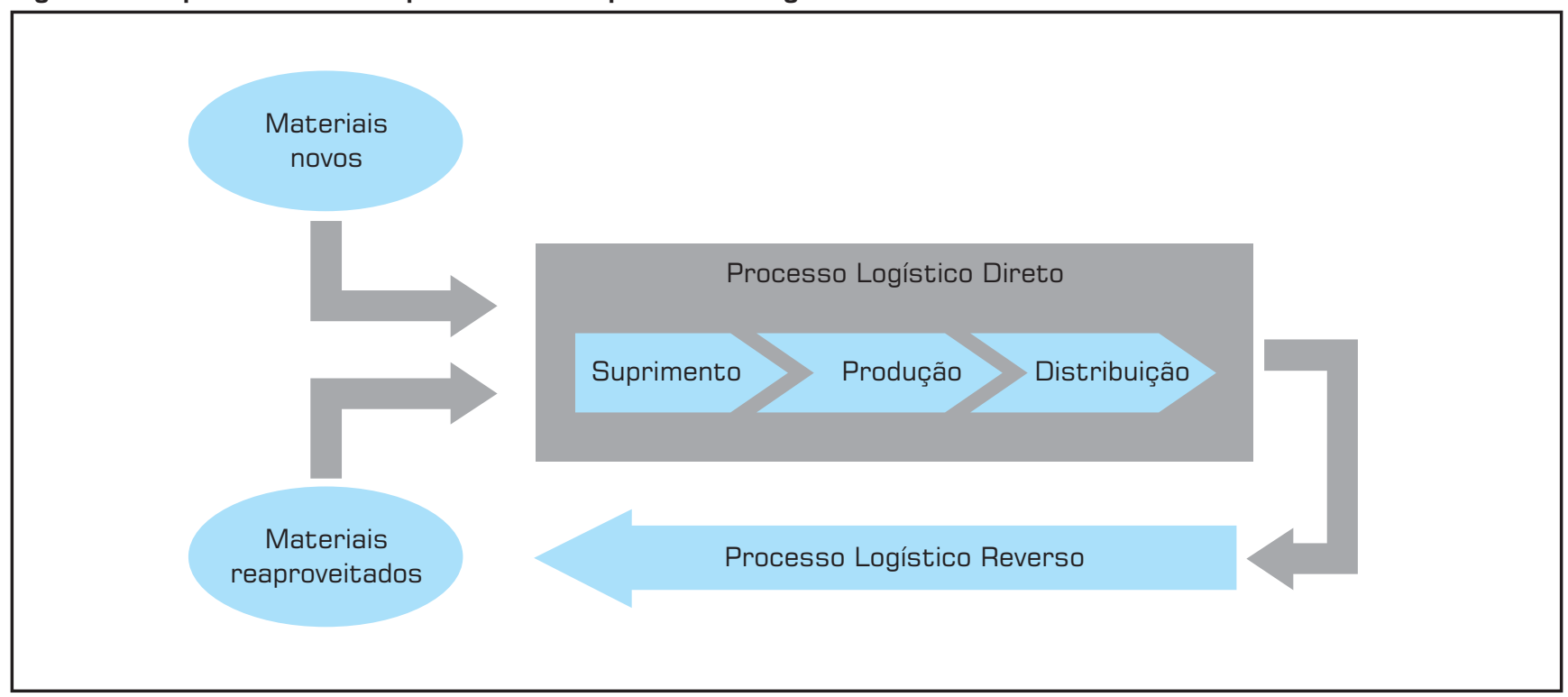

Fonte: Lacerda, 2002 
têm manifestado seu comprometimento por meio de declarações de missões empresariais. No entanto, segundo Liva, Pontello e Oliveira (2004), objetivos econômicos ainda são os mais evidentes na implementação de programas de logística reversa.

\section{Embalagens retornáveis ou multiusos}

Um problema relevante em logística reversa, que pode oferecer benefícios ambientais e econômicos, e que é central nesta pesquisa, é o retorno de embalagens. O problema transcende ao âmbito da manufatura, haja vista que, para produtos de montagem complexa ou que requerem combinações de peças, ou ainda que devem passar por longos translados, o próprio projeto de produto pode ser afetado.

Embalagens podem ser do tipo descartável, que perdem grande parte do valor durante o consumo do produto, tais como as garrafas PET, ou retornáveis, cujo valor sobrevive ao consumo do produto, tais como garrafas de vidro. No primeiro caso, o papel da logística reversa é recolher e dar destinação ao material, ou, no máximo, extrair um valor residual. No segundo caso, é recolocar o material no ciclo produtivo, extraindo do mesmo um valor pleno.

O problema das embalagens parece ser relevante a tal ponto que Liva, Pontello e Oliveira (2004) identificam uma logística reversa específica para embalagens, ao par das logísticas de pós-venda e pós-consumo. Nhan, Souza e Aguiar (2003) comentam que, com mercados cada vez mais afastados, além das embalagens primárias, surge a necessidade da unidade conteinerizada, para longa distância. Segundo estes autores, há uma tendência mundial de se usarem embalagens retornáveis, reutilizáveis ou de múltiplas viagens (multiways). Especificamente quanto ao retorno de embalagens, Lima e Caixeta Filho (2001) comentam que este fluxo pode reduzir desperdícios de valores e riscos ao ambiente, pela reutilização, recuperação e reciclagem dos materiais de embalagens.

A embalagem de interesse para esta pesquisa é o contenedor industrial retornável. Um contenedor retornável é um tipo de embalagem secundária que pode ser usada mais de uma vez da mesma forma, ao contrário dos contenedores do tipo one-way, descartados tão logo se dê o uso do produto. Para tanto, um sistema de gerenciamento de retorno deve ser montado, para que os contenedores estejam disponíveis no ponto e no momento em que forem requisitados. $\mathrm{O}$ sistema de gerenciamento deve ter como meta a coleta do contenedor vazio no atual usuário e o seu transporte até o próximo usuário. O contenedor deve chegar limpo, íntegro e identificado com os dados da próxima transação (KROON; VRIJENS, 1995).
Outra necessidade gerencial que pode surgir na gestão de embalagens retornáveis é a determinação de rotas. Embalagens reutilizáveis e bens a reciclar ou remanufaturar são transportados na direção oposta à distribuição. Se ambas as tarefas são executadas pela mesma infra-estrutura de transporte, um problema de roteamento surge, e sua solução deve considerar, simultaneamente, tanto a via direta como a reversa, determinando uma rota ótima com entregas e coletas na mesma ronda (DETHLOFF, 2001).

\section{interesse de empresários, praticantes pesquisadores por logística reversa aportado novas perspectivas ao debate e ainda não se chegou a uma visão unificada sobre o tema.}

Leite (2003) compara embalagens descartáveis e retornáveis. Segundo o autor, as embalagens retornáveis possuem os mesmos inconvenientes das descartáveis, tais como os custos do transporte direto, transporte de retorno, administração de fluxos, recepção, limpeza, reparos eventuais, armazenamento e de capital investido. Contudo, além dos benefícios ambientais, embalagens retornáveis também podem oferecer outros tipos de benefícios: (i) conferir maior proteção aos produtos; (ii) oferecer ao usuário maior flexibilidade à medida que mudarem os requisitos legais; ou (iii) se a empresa não possui mais nenhuma aplicação para as embalagens, elas podem retornar ao fabricante como material reciclado, podendo ser utilizadas em novas embalagens.

Segundo Leite (2003), há três aspectos que devem ser considerados em decisões sobre embalagens: (i) os sistemas de produção de alta velocidade de resposta (just-in-time), nos quais a exigência de rápida alimentação das linhas de montagem, alta freqüência de entregas e tempos de atravessamento curtos favorecem o uso de embalagens retornáveis; (ii) a crescente consciência ecológica empresarial, pelo impacto de seus produtos, embalagens e acessórios no meioambiente; e (iii) o desenvolvimento de empresas prestadoras de serviço de locação de embalagens e acessórios, que permitem reduções de custo aos utilizadores.

Rogers e Tibben-Lembke (2001) comentam que custos de transporte não devem ser os únicos a serem considerados em decisões sobre embalagens retornáveis, já que estas também afetarão custos de manuseio e rastreamento de embarques. Os autores destacam a importância de se desenvolverem embalagens leves e resistentes, tendo em vista que muitos custos de embarque estão associados ao peso da carga e à 
necessidade de acondicionamento para prevenção de dano no transporte. $\mathrm{O}$ aproveitamento do espaço das embalagens retornáveis também é destacado pelos autores, haja vista que embalagens padronizadas podem fazer com que haja espaço perdido e prejudicar o aproveitamento dos contêineres e veículos, aumentando o custo de transporte. O ganho em ergonomia também é relevante, de modo a preservar a saúde ocupacional dos operadores, tanto na fabricação como no uso e descarte da embalagem.

O objetivo de pesquisa foi enumerar e analisar os ganhos obtidos pela utilização de embalagens descartáveis na exportação de cabeçotes de motores a diesel, do Brasil para os Estados Unidos, por uma empresa montadora de motores a diesel. O processo de exportação tem operado continuamente, com embalagens retornáveis, desde novembro de 2003. Como os eventos de interesse são únicos e as informações relativas ao mesmo estão organizadas e podem ser recuperadas, recai-se no estudo de caso.

\section{A PESQUISA}

para gerar ou reforçar uma teoria; (iv) estabelece sondagens plausíveis acerca de uma teoria já proposta; e (v) oferece a possibilidade de apoiar ou refutar uma teoria já sondada. Nestes três últimos tipos de casos, os objetivos seriam, em graduações, a exploração, a geração e o teste de teorias. A contribuição do presente caso é do primeiro e do segundo tipo: o caso oferece uma descrição do objeto de pesquisa e os pesquisadores identificaram regularidades, ao longo do tempo, propondo postulados que poderão ser reforçados ou refutados posteriormente, por outros casos.

A equipe de pesquisa foi composta pelo analista de logística praticante, principal responsável, na empresa, pela condução do projeto empresarial de implantação de embalagens retornáveis, e por um pesquisador acadêmico, ligado a programa de pós-graduação em engenharia de produção.

A metodologia de trabalho adotada pela equipe de pesquisa foi: (i) revisão bibliográfica sobre o tema, para formar uma base de comparação com as informações de campo que seriam coletadas a seguir; (ii) programa de visitas à fábrica, no qual, após conhecimento da operação, foram realizadas entrevistas em profundidade com quatro executivos, responsáveis pelo desenvolvimento e testes da embalagem; pela contratação dos modais de transporte envolvidos na operação; pelo controle das operações envolvidas no projeto; e pela análise financeira envolvida no projeto; (iii) análise dos documentos in-

O estudo de caso é uma estratégia de pesquisa que examina em profundidade um fenômeno contemporâneo, dentro de seu contexto, especialmente quando os limites entre fenômeno e contexto não são claros, definidos e evidentes. O estudo de caso pode ser exploratório, visando a levantar questões e hipóteses para futuros estudos; descritivo, em que se buscam associações entre variáveis, tanto qualitativas como quantitativas; ou explanatório, no qual se faz uma descrição dos fatos acrescentando-se explicações aceitáveis e verificáveis destes fatos. Como não exige um esquema conceitual rígido, pode ser usado em situações nas quais o pesquisador não possui um conhecimento a priori. Admitese ainda que, ao longo do estudo, os tópicos sob investigação possam ser reorganizados e recombinados segundo critérios emergentes (YIN, 2001).

Segundo Eckstein (1975, apud ROESCH, 1999), há cinco modos pelos quais um estudo de caso pode contribuir para uma teoria: (i) oferece, para posteriores estudos, uma descrição profunda e específica de um objeto; (ii) o pesquisador interpreta eventuais regularidades presentes no objeto como uma evidência de postulados teóricos mais gerais ou refuta postulados teóricos que deveriam ter sido verificados e não o foram; (iii) uma situação é deliberadamente construída oferecidos pelo pesquisador praticante e pelos executivos entrevistados, nos quais foi possível recuperar a motivação e os principais aspectos estruturais do projeto; (iv) análise de relatórios de informação gerenciais, com os quais foi possível organizar e comparar alguns dos resultados mensurados antes e depois da adoção das embalagens retornáveis; (v) análise crítica de aspectos observados e organizados no caso, comparados com a teoria anteriormente revisada; e (vi) formalização, em artigo, dos achados de pesquisa. Todo o projeto de engenharia da embalagem e logística foi concebido e conduzido com recursos humanos e materiais ligados à empresa que sediou o estudo.

\section{Informações Coletadas: Relato do Caso}

A seguir apresentam-se, em forma de relato, as informações obtidas pelos instrumentos de pesquisa citados. Relatam-se os antecedentes (como era) e a solução adotada (como ficou). Os benefícios da mudança são relatados e discutidos na próxima sessão.

A empresa estudada monta, além de motores completos, cabeçotes utilizados em duas famílias de motores, cuja montagem final ocorre em um cliente, em Melrose Park, nos ternos da empresa, nomeadamente comunicações internas, 
EUA. O início das exportações de cabeçotes para Melrose Park ocorreu em novembro de 2003 e as primeiras entregas de motores no mercado interno norte-americano ocorreram no primeiro trimestre de 2004.

A motivação inicial do projeto foi a exigência do cliente em receber, exclusivamente, materiais embarcados com embalagens retornáveis. Como a exportação para outros destinos até então se dava em embalagens de papelão, descartáveis, considerou-se inicialmente usar uma embalagem descartável de papelão reforçado, com capacidade de empilhamento triplo no contêiner. A garantia de integridade do cabeçote, contra oxidação, é de apenas três meses, já que decidiu-se não aplicar óleo protetivo nas faces usinadas. A presença de óleo exigiria lavagem das peças no destino final e procedimento de disposição para o óleo.

A manutenção do conceito de embalagem descartável de papelão implicaria receber as remessas em armazém, próximo a Melrose Park, e realizar a troca de embalagem, antes da entrega final. Resultaria acréscimo de custo e um potencial problema de qualidade para os cabeçotes, após três meses de armazenagem. O conceito de embalagens descartáveis, além de consumir recursos naturais e gerar resíduos, aproveita mal, volumetricamente, o contêiner marítimo. Embalagens de papelão descartáveis comportam menos cabeçotes, exigem racks e bandejas metálicos para o acondicionamento e proteção, e restringem o contêiner por volume, não podendo ser transportado o máximo peso líquido possível.

Devido a estes problemas, a empresa decidiu mudar o conceito e exportar diretamente em embalagens retornáveis. A motivação inicial, portanto, foi comercial: atender a uma determinação do cliente, mas também existiu um motivador econômico e de valor para o cliente: atender à determinação com um custo mais baixo e sem riscos à qualidade dos itens.

Desenvolveu-se então uma embalagem feita de material plástico, específica para os cabeçotes, diferente das embalagens padronizadas até então utilizadas, de madeira ou papelão. A nova embalagem é composta por bandejas formadas a vácuo e palete especialmente desenvolvido. Eliminou-se a necessidade de racks e bandejas metálicas, até então utilizadas. Adicionalmente, há espaço para protetores personalisados contra oxidação, dispensando o uso de óleo protetivo.

As bandejas são de PEAD de 7mm (Polietileno de Alta Densidade) e o palete com tecnologia twinsheet (processo com duas chapas), resultando uma relação carga por embalagem de 3,6\% por viagem, considerada excepcional, sabendo-se ainda que, neste peso, se inclui a proteção contra oxidação. A embalagem também prevê proteção anticorrosiva por sacos plásticos de VCI (Volatile Corrosion Inhibitors ): um saco espesso em cada nível, e sacos menos espessos para cada cabeçote, agregados a mais quatro $s a$ chets de VCI por embalagem.

A nova embalagem não gera resíduos nem custos com disposição e aproveita totalmente o volume do contêiner de vinte pés, chegando a duzentos e quarenta cabeçotes por contêiner, ao invés dos duzentos e dezesseis anteriores. Cada embalagem transporta doze cabeçotes, em dois níveis de seis peças cada. Um cabeçote pesa $110 \mathrm{~kg}$. O peso total alcança $1.370 \mathrm{~kg}$ por caixa com doze cabeçotes, contra os $690 \mathrm{~kg}$ anteriores, por caixa de papelão com seis cabeçotes. O conjunto para doze cabeçotes (palete e três bandejas de plástico) pesa $50 \mathrm{~kg}$, contra os $30 \mathrm{~kg}$ anteriores, de papelão, para seis cabeçotes. Estas características comparadas de desempenho são resumidas na Tabela 1. Há ganho de ocupação de volume no contêiner. Os pesos unitários são próximos, mas carregase mais de $10 \%$ a mais de peso no mesmo volume.

As principais características da nova embalagem são: (i) a capacidade estática para empilhamento de [1 + 2] embalagens no armazém dos EUA, o que representava um peso total de $4.200 \mathrm{~kg}$ sobre o último palete, e uma capacidade dinâmica para transporte de $[1+1]$ embalagem de $2.800 \mathrm{~kg}$; (ii) a capacidade de travamento de uma embalagem sobre a outra; e (iii) o travamento dos cabeçotes na própria bandeja.

Tabela 1: Características comparadas de desempenho entre conceitos de embalagem.

\begin{tabular}{|l|c|c|}
\hline \multicolumn{1}{|c|}{ GARAGTERÍstica DE DESEMPENHO } & $\begin{array}{c}\text { EMBALAGEM } \\
\text { ANTERIOR, PAPELÃO }\end{array}$ & 12 \\
\hline Cabeçotes em cada embalagem & 6 & 50 \\
\hline Peso da embalagem vazia, em kg & 30 & 1.370 \\
\hline Peso de uma embalagem carregada, em kg & 690 & $1.370 / 12=114$ \\
\hline Peso transportado, por cabeçote, em kg & $690 / 6=115$ & 240 \\
\hline Cabeçotes por contêiner & 216 & 27.360 \\
\hline Peso por contêiner, em kg & 24.840 & \\
\hline
\end{tabular}


Estas condições foram verificadas em testes dinâmicos práticos, em viagens de ida e volta do Rio Grande do Sul a São Paulo, testes de resistência do palete no fornecedor com $4.600 \mathrm{~kg}$ de carga, e teste de vibração e oscilação (requisito do cliente para aprovação da embalagem), segundo normas ASTM (American Society for Testing and Materials), executados no Centro Tecnológico do IPT (Instituto de Pesquisas Tecnológicas) em São Paulo. Em todos os ensaios, a embalagem foi aprovada.

A embalagem não requer peação do contêiner marítimo. A peação é o processo de travamento de cargas dentro dos contêineres, para evitar deslocamentos e escorregamentos durante o transporte marítimo. Na Figura 2, observam-se detalhes do sistema de travamento empregado.

Para cálculos de custos logísticos, foi considerado o fluxo de retorno das embalagens.

Semanalmente, a empresa despacha do Brasil sete contêineres de vinte pés para o armazém nos EUA, onde mantém um estoque capaz de sustentar a operação por, em média, trinta dias. A linha de montagem de Melrose Park é alimentada, diariamente, do armazém, por um processo de SMI (gerenciamento de inventário pelo fornecedor), controlado eletronicamente, que mantém, na linha de montagem, um pulmão de quatro horas de produção. A função do pulmão é compensar eventuais variações na cadeia de abastecimento que liga o armazém à planta. O retorno das embalagens vazias ocorre semanalmente, na mesma quantidade das embalagens despachadas. A cada sete contêineres de vinte pés enviados, a empresa retorna um contêiner de quarenta pés com embalagens vazias.
Para o dimensionamento da quantidade de embalagens necessárias para o fluxo, mediram-se e somaram-se os tempos médios das etapas, o que resultou em um tempo médio de trânsito total de cento e trinta dias. Este é o tempo médio entre a data de envio de uma embalagem até o seu retorno ao Rio Grande do Sul, e sua recolocação na linha de montagem.

Na Figura 3, representam-se os fluxos das embalagens e os trajetos envolvidos na operação.

Na Tabela 2, observam-se as etapas parciais e a sua duração média, em dias. Preferiu-se incorporar todos os atrasos em uma única etapa, cujo valor médio foi de vinte dias. Ressalta-se que estes valores são as médias das grandezas. As variabilidades características de variáveis aleatórias não foram informadas, por não terem sido encontradas nos registros disponíveis. A soma das médias é possível graças ao teorema do limite central, segundo o qual a média de uma soma de variáveis aleatórias tende à soma das médias das variáveis, quando a quantidade de variáveis cresce.

\section{DISCUSSÃO}

O capital investido inicialmente nas embalagens retornáveis foi de um milhão de reais, considerado elevado pela empresa, na ocasião, em meados de 2003. A empresa adquiriu de uma única vez as embalagens retornáveis, ao passo que anteriormente precisava uma estrutura de aquisição de embalagens descartáveis para cada embarque.

$\mathrm{O}$ uso do novo conceito tem gerado uma economia que os-

Figura 2: Sistema de travamento do palete com a bandeja no empilhamento.

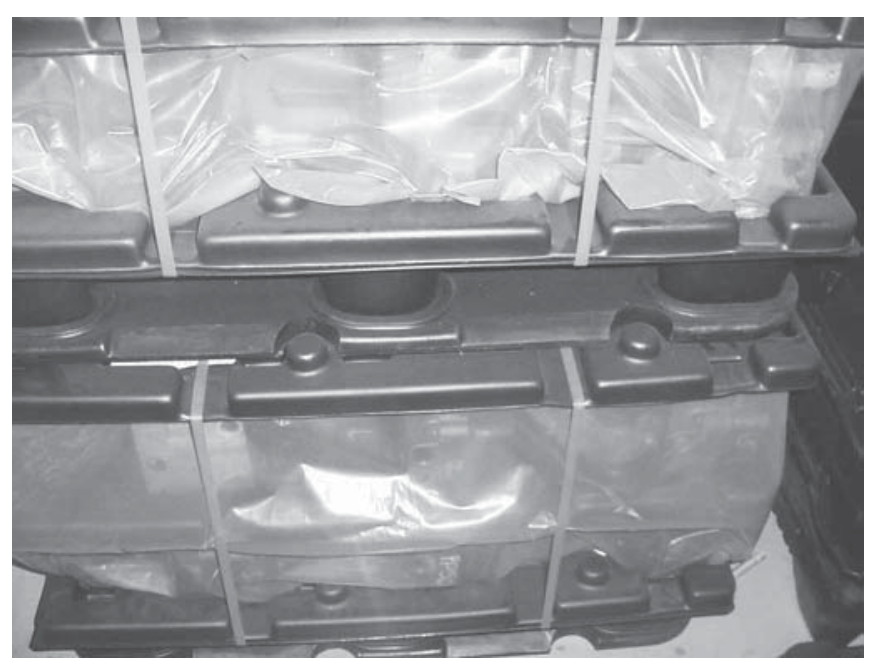

Fonte: International, 2004. 
cila ao redor de R $\$ 950$ mil por ano, em redução de gastos com embalagens, a partir do segundo ano do projeto. O tempo de retorno do investimento foi estimado em dezoito meses, a vida útil do projeto em dez anos e a depreciação da embalagem em cinco anos. Estas são estimativas sobre grandezas aleatórias, tais como o custo de logística, de produção de embalagens e de quantidade de produção, portanto os retornos citados devem ser tomados apenas como as melhores expectativas possíveis.

\section{Figura 3: Representação do transporte das embalagens.}

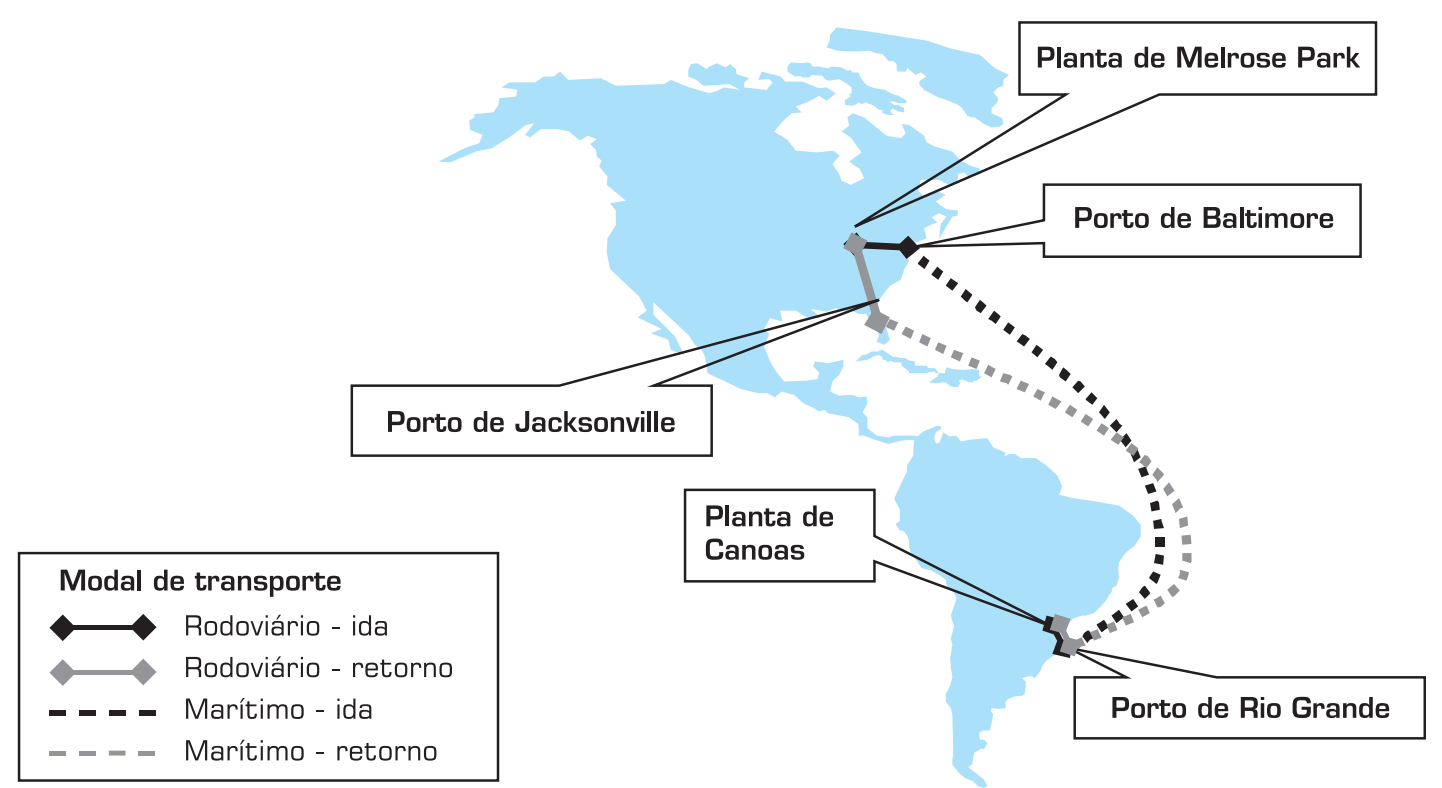

Fonte: empresa.

Tabela 2: Durações médias das etapas do processo de uso da embalagem retornável.

ETAPA DO PROCEDIMENTO

\section{MÉDIA DE DIAS NA ETAPA}

Estoque em Canoas

Despacho, trânsito até o porto, alfândega no Brasil

Trânsito até os EUA

Alfândega nos EUA e trânsito até Melrose Park

Estoque em Melrose Park antes do uso

Estoque em Melrose Park após o uso (vazias]

Despacho, trânsito até o porto, alfândega nos EUA

Trânsito até o Brasil

Alfândega no Brasil e trânsito até Canoas

Atrasos em embarques

Total

130 dias

Fonte: International, 2004 
A viabilidade econômica do projeto fez com que todos os novos projetos de exportação de longa distância (Estados Unidos e Europa) utilizem embalagens retornáveis.

Interessa discutir aspectos deste sucesso. São muitas as questões envolvidas sobre as vantagens e desvantagens de se utilizarem embalagens descartáveis ou retornáveis.

\section{A empresa estudada melhorou um Ados mais importantes dos seus processos de exportação, sob o ponto de vista da logística reversa e, em particular, de embalagens retornáveis.}

retornáveis, o balanço de custos é favorável. A empresa emprega três pessoas no Brasil e três pessoas nos Estados Unidos, dedicadas à administração logística da operação, além de um operador logístico para o armazenamento, que existiriam com qualquer das duas situações, portanto não configuram aumento de custo com a opção.

Finaliza-se a discussão sumarizando, no Quadro 1, alguns dos resultados observados após a implantação do retorno de embalagens.

Também é um objetivo de pesquisa uma análise crítica dos resultados obtidos, à luz do referencial teórico disponível. A bibliografia cita a importância de se utilizarem materiais recicláveis na fabricação de embalagens ou na sua utilização propriamente dita. Tal aspecto foi verificado objetivamente no estudo do caso.

A bibliografia também cita que efeitos, tais

Observa-se que a empresa conseguiu agregar três tipos de valor com o uso da logística reversa: (i) econômico, propiciando os retornos já citados; (ii) ecológico, com a redução de resíduos gerados; e (iii) logísticos, pelo melhor aproveitamento dos contêineres marítimos. Além da redução no custo da embalagem por viagem, a empresa ainda obteve outros ganhos: a maior (i) proteção que as novas embalagens conferem aos cabeçotes; (ii) flexibilidade para efetuar alterações na embalagem frente à requisitos legais; e (iii) reciclagem das embalagens danificadas ou em fim da vida útil, efetuada pelo próprio fornecedor da embalagem.

O principal fator que levou a empresa a adotar as embalagens retornáveis foi econômico. A vontade de não perder uma oportunidade de fornecimento e a redução nos custos logísticos propiciada foram decisivas para a implementação. Isso comprova as afirmações da bibliografia consultada, de que os principais motivos para o uso de embalagens retornáveis no Brasil ainda estão relacionados com a redução de custos e aumento de valor econômico.

Observa-se que, ao passo que a literatura argumenta que os custos de transporte aumentam com o uso de embalagens retornáveis, no caso em estudo houve uma redução, devido a um novo desenho da embalagem dos cabeçotes, com volume e peso menores, que possibilitou o envio de mais cabeçotes por embarque. Outro aspecto destacado pela bibliografia diz respeito aos custos e dificuldades envolvidas na rastreabilidade das embalagens retornáveis. Observa-se que a empresa vem utilizando-se de um controle manual das embalagens, sujeito a erros na localização das mesmas, que deverá evoluir em direção a rastreamento automático.

$\mathrm{O}$ transporte de retorno gera um custo que não existiria com embalagens descartáveis, pois passou-se a enviar ao Brasil um contêiner com embalagens vazias. Contudo, devido ao maior número de cabeçotes enviados por embarque, e a ser único o custo de aquisição das embalagens como danos ao ambiente e o uso de materiais auxiliares, devem ser minimizados durante a logística reversa. Um resultado que emergiu ao longo do projeto e que se coaduna com o que foi citado é a melhoria na proteção contra a oxidação do cabeçote. Foi um objetivo de projeto a proteção contra oxidação.

Como os cabeçotes são peças completamente usinadas, os riscos são grandes, mas as proteções utilizadas foram demasiadas. Não é mais necessário utilizar os quatro $s a$ chets originais de VCI por cabeçote, além de um saco VCI individual e outro coletivo que engloba os seis cabeçotes de cada nível. Segundo a empresa, estão em andamento testes para eliminar o saco individual e enviar somente o saco coletivo, reduzindo a geração de resíduos de sacos plásticos da proteção, cuja disposição ocorre nos Estados Unidos.

A bibliografia alerta ainda para alguns inconvenientes como, por exemplo, os custos de recebimento e de limpeza eventual das embalagens antes de serem novamente utilizadas no processo produtivo. A empresa sabe que será necessária limpeza adicional, pois as embalagens chegam contaminadas com poeira nas bandejas e no palete, o que não pode chegar à linha de montagem para que não contaminem os cabeçotes. Os custos com limpeza foram previstos no desenvolvimento do projeto, mas até hoje a forma desta limpeza ainda não está definida. Provavelmente deverão ser contratadas empresas especializadas para o serviço de limpeza e de manutenção do estoque de embalagens vazias.

Finalmente, a bibliografia informa que a redução de custos financeiros seria o motivo principal para a adoção da logística reversa, o que também foi confirmado pelo estudo.

\section{CONCLUSÃO}

A empresa estudada melhorou um dos mais importantes dos seus processos de exportação, sob o ponto de vista da 
Quadro 1: Vantagens e desvantagens sob o ponto de vista da logística reversa no caso em estudo.

\begin{tabular}{|c|c|}
\hline TIPO & ASPEGTOS RELEVANTES \\
\hline $\begin{array}{l}\text { Vantagens } \\
\text { ecológicas }\end{array}$ & $\begin{array}{l}\text { Eliminação da geração de resíduos de papelão, com o uso de: } \\
\text { - Reciclagem das embalagens plásticas após o término da sua vida útil; } \\
\text { - Reciclagem das embalagens danificadas. } \\
\text { Os cabeçotes viajam sem óleo protetivo, eliminando a lavagem no destino final. }\end{array}$ \\
\hline $\begin{array}{l}\text { Vantagens } \\
\text { econômicas }\end{array}$ & $\begin{array}{l}\text { O tempo de retorno do investimento foi estimado em dezoito meses, a vida útil do projeto em dez } \\
\text { anos e a economia anual tem se mantido ao redor de R\$ } 950 \text { mil, por: } \\
\text { - Redução no custo da embalagem por viagem; } \\
\text { - Capacidade de empilhamento estático de três embalagens no armazém, devido à alta } \\
\text { capacidade de carga dos paletes, reduzindo os custos de armazenagem; e } \\
\text { - Maior proteção que as embalagens retornáveis oferecem aos cabeçotes. }\end{array}$ \\
\hline $\begin{array}{l}\text { Vantagens } \\
\text { logísticas }\end{array}$ & $\begin{array}{l}\text { Redução na complexidade das operações, obtida com o uso de: } \\
\text { - Melhor aproveitamento do espaço interno dos contêineres; } \\
\text { - Não há necessidade de peação do contêiner; } \\
\text { - As embalagens são utilizadas diretamente na linha de montagem do cliente; } \\
\text { - Fluxo de retorno de embalagens balanceado com a mesma quantidade enviada, a cada sete } \\
\text { contêineres de vinte pés com vinte embalagens retorna um contêiner de quarenta pés com } \\
140 \text { embalagens dos Estados Unidos; e } \\
\text { - O sistema de proteção anti-oxidação com VCl permite transporte limpo e seguro. }\end{array}$ \\
\hline Desvantagens & $\begin{array}{l}\text { Aspectos econômicos e logísticos: } \\
\text { - Aspectos econômicos: foi necessário um investimento inicial elevado, de um milhão de reais, } \\
\text { pois as embalagens foram adquiridas de uma única vez e há reposição; } \\
\text { - Aspectos logísticos: há dificuldades de rastreamento das embalagens vazias, é necessário um } \\
\text { transporte de retorno e mais controle na operação de retorno. }\end{array}$ \\
\hline
\end{tabular}

logística reversa e, em particular, de embalagens retornáveis. O estudo permitiu identificar todos os ganhos oriundos da implementação, mesmo que os ganhos financeiros tenham sido o fator-chave e o principal motivador para o investimento em embalagens retornáveis.

O estudo também mostrou a minimização de impactos ambientais resultantes da operação, eliminando a geração de resíduos das embalagens usadas e a exigência de novos materiais, pois o fornecedor passou a receber e reprocessar as embalagens danificadas ou que já haviam chegado ao fim da sua vida útil. $\mathrm{O}$ fornecedor usa embalagens velhas como materia-prima para novas. Finalmente, como último grande ganho, a operação logística tornou-se menos complexa e menos sujeita às variabilidades naturais deste tipo de operação.

Entende-se que a contribuição desta pesquisa seja a evidenciação de que, em um caso, a introdução de uma prática específica da logística reversa, o uso de embalagens retornáveis, trouxe três tipos de resultados a uma empresa exportadora: benefícios financeiros, redução de ataques ambientais e benefícios logísticos.
Como sugestão de continuidade, outra preocupação que merece atenção é com relação ao sistema de controle do fluxo de embalagens entre Brasil e Estados Unidos. A bibliografia já alerta sobre o controle operacional do processo para fins de rastreabilidade das embalagens e isto é algo que a empresa ainda não exerce de uma forma eficaz. Seria importante que fosse desenvolvido um sistema de código de barras anexado aos paletes por meio de uma etiqueta para que se pudesse efetuar o controle via sistema de leitura ou um próprio sistema RFID (Radio Frequency Identification). Os pontos de verificação seriam o despacho no setor de expedição da fábrica, o porto no Brasil, o porto nos Estados Unidos, o armazém nos Estados Unidos e a rota reversa. O sistema atual da empresa baseia-se em planilha de controle e não parece mais ser eficaz para a atual exigência de rastreabilidade do processo.

Outra linha de continuidade possível seria inserir cálculos de variabilidade nas grandezas aleatórias pesquisadas, já que a empresa tem registrado apenas as médias das mesmas.

Artigo recebido em 31/05/2006

Aprovado para publicação em 10/05/2007 


\section{- Referências}

BRITO, M; DEKKER, R. A framework for reverse logistics, 2003. ERIM Report Series Research In Management, n.. ERS2003-045-LIS, Erasmus Research Institute of Management (ERIM). Disponível em: $<$ https://dspace.ubib.eur.nl/retrieve/439/ ERS-2003-045-LIS > . Acesso em maio 2006.

CHOUINARD, M.; D'AMOURS, S.; AITKADI, D. Integration of reverse logistics activities within a supply chain information system. Computers in Industry, v. 56, n. 1, p. 105-124, 2005.

C.L.M. Council of Logistics Management. Reuse And Recycling Reverse Logistics Opportunities. Illinois: Council of Logistics Management, 1993.

DAUGHERTY, P.; MYERS, M.; RICHEY, R. Information support for reverse logistics: the influence of relationship commitment. Journal of Business Logistics, v. 23 n. 1 , p. 85-106, 2002

DAUGHERTY, P.; RICHEY, R.; GENCHEV, S.; CHEN, H. Reverse logistics: superior performance through focused resource commitments to information technology. Transportation Research Part E: Logistics and Transportation Review, v. 41, n. 2 , p. 77-92, 2005

DETHLOFF, J. Vehicle routing and reverse logistics: the vehicle routing problem with simultaneous delivery and pick-up. OR Spectrum, v. 23, n. 1, p. 79-96, 2001.

DOWLATSHAHI, S. Developing a theory of reverse logistics. Interfaces, v. 30 n. 3 , p. $143-155,2000$
GAITHER, N.; FRAZIER, G. Administração da Produção e Operações. São Paulo: Thomson, 2002.

FLEISCHMANN M. et al. Quantitative models for reverse logistics: a review. European Journal of Operational Research, v. 103 , n. 1 , p. $1-17,1997$

FLEISCHMANN, M. et al. The impact of product recovery on logistics network design, Production and Operations Management, v. 10 , n. 2, p. 156-173, 2001

GEORGIADIS, P.; VLACHOS, D. The effect of environmental parameters on product recovery. European Journal of Operational Research. v. 157, n. 2, p. 449-464, 2004.

KROON, L.; VRIJENS, G. Returnable containers: an example of reverse logistics. International Journal of Physical Distribution \& Logistics Management, v. 25, n. 2, p. 56-68, 1995.

KRUMWIEDE D.; SHEU C. A model for reverse logistics entry by third-party providers. Omega, v. 30 , n. 5 , p. 325 333, 2000.

LACERDA, L. Logística reversa: uma visão sobre os conceitos básicos e as práticas operacionais. Rio de Janeiro: COPPEAD/ UFRJ, 2002.

LEITE, P. Logística Reversa: Meio ambiente e competitividade. São Paulo: Prentice Hall, 2003.
LEITE, P.; BRITO, E. Reverse Logistics on returned products: is Brazil ready for the increasing challenge? Anais do Congresso Balas 2003. São Paulo, 2003.

LIMA, L.; CAIXETA FILHO, J. Conceitos e práticas de logística reversa. Revista Tecnologística, ano VI, n. 66, p. 54-58, 2001.

LIVA, P.; PONTELO, V; OLIVEIRA, W. Logística Reversa. In: Tecnologia Industrial - Logística. Disponível em: < http://www. ietec.com.br/ietec/techoje/ > . Acesso em 21 abril 2004

MINNER. S. Strategic Safety Stocks in Reverse Logistics Supply Chains. International Journal of Production Economics, v. 71 , n. $1-3$, p. $417-428$, 2001.

NHAN, A.; SOUZA, C.; AGUIAR, R. Logística reversa no Brasil: a visão dos especialistas. Anais do XXIII ENEGEP, Ouro Preto, 2003.

POHLEN, T.; FARRIS, M. Reverse Logistics in Plastics Recycling. International Journal of Physical Distribution and LogisticsManagement, v. 22, n. 7 , p. 34-47, 1992

PRAHINSKI, C.; KOCABASOGLU, C. Empirical research opportunities in reverse supply chains. Omega, v. 34, n. 6, p. 519-532, 2006.

RICHEY, R. et al. Developing effective reverse logistics programs. Industrial Marketing Management, v. 34, n. 8, p. 830-840, 2005.
RLEC - Reverse Logistics Executive Council. Disponível em: <www.rlec. org/index.html>. Acesso em: 21 abril 2004

ROESCH, S. Projetos de estágio e de pesquisa em administração: Guia para estágios, trabalhos de conclusão, dissertações e estudos de caso. São Paulo: Atlas, 1999.

ROGERS, D.; TIBBEN-LEMBKE, R. An examination of reverse logistics practices. Journal of Business Logistics, v. 22, n. 2, p. 129-148, 2001.

RODRIGUES, G.; PIZZOLATO, N. A logística reversa nos centros de distribuição de lojas de departamento. Anais do XXIII ENEGEP, Ouro Preto, 2003.

ROSENAU, W. et al. Returnable/reusable logistical packaging a capital budgeting investment decision framework, Journal of Business Logistics, v. 17, n. 2, p. $139-165,1996$

SHIH L. Reverse logistics system planning for recycling electrical appliances and computers in Taiwan Resources Conservation and Recycling, v. 32, n. 1 , p. 55-72, 2001

SLIJKHUIS, C. Logística reversa: reciclagem de embalagens de transporte. disponível em: < http://www.guiadelogistica.com. br/ARTIGO19.htm > . Acesso em: 21 abril 2004.

YIN, R. Estudo de caso: planejamento e método. Porto Alegre: Bookman, 2001.

\section{- Reconhecimentos}

Deseja-se reconhecer o papel da MWM International, de Canoas, RS, empresa fabricante de motores a diesel, que sediou o estudo. Também deseja-se reconhecer a importância dada pela UAP\&PG da UNISINOS aos esforços de pesquisa do PPGEPS-UNISINOS. Por fim, salientam-se os comentários dos referees anônimos, que contribuíram para a forma final do artigo.

\section{- Sobre os autores}

\section{Diogo Adlmaier}

Graduado em Engenharia de Produção pela UNISINOS e especialista em Logística pela UNILASALLE

Engenheiro de Logística da MWM International Motores

End.: Av. Unisinos 950, São Leopoldo - RS - 93022-000

E-mail: diogo.adlmaier@weatherford.com

\section{Miguel Afonso Sellitto}

Doutor em Engenharia de Produção

Professor e pesquisador no Programa de Pós-Graduação em Engenharia de Produção e Sistemas - PPGEPS

Universidade do Vale do Rio dos Sinos - UNISINOS

End.: Av. Unisinos 950, São Leopoldo -RS - 93022-000

Tel.: (51) 3590-1122

E-mail: sellitto@unisinos.br 